\title{
Clinical Performance of Toris K Contact Lens in Patients with Moderate to Advanced Keratoconus: A Real Life Retrospective Analysis
}

\author{
Ihsan Yilmaz, Ferah Ozcelik, Berna Basarir, Gokhan Demir, \\ Gonul Durusoy, and Muhittin Taskapili \\ Beyoglu Eye Training and Research Hospital, 34420 Istanbul, Turkey \\ Correspondence should be addressed to Ihsan Yilmaz; ihsanyilmaz.dr@gmail.com
}

Received 7 January 2016; Revised 1 March 2016; Accepted 14 March 2016

Academic Editor: Jesús Pintor

Copyright (C) 2016 Ihsan Yilmaz et al. This is an open access article distributed under the Creative Commons Attribution License, which permits unrestricted use, distribution, and reproduction in any medium, provided the original work is properly cited.

Objectives. To evaluate the visual performance of Toris $\mathrm{K}$ soft contact lenses in patients with moderate-to-advanced keratoconus and also to compare the results according to cone types, cone location, and severity of keratoconus. Materials and Methods. Sixty eyes of 40 participants were included in this retrospective study. Uncorrected visual acuity (UCVA), best-spectacle corrected visual acuity (BCVA), best-contact lens corrected visual acuity (BCLCVA), and comfort rating via visual analogue scales (VAS) were measured. Results. The mean age was $27.3 \pm 8.6$ years (range: 18 to 54 ). The mean logMAR UCVA, BCVA, and BCLCVA were $0.85 \pm 0.38$ (range: $0.30-1.30), 0.47 \pm 0.27$ (range: $0.10-1.30$ ), and $0.16 \pm 0.20$ (range: $0-1.00$ ). There were significant increases in visual acuities with contact lenses $(p<.05)$. BCLCVA was significantly better in oval type than globus type $(p=.022)$. UCVA and BCLCVA were significantly better in moderate keratoconus group $(p=.015, p=.018)$. The mean line gain in Snellen was $3.6 \pm 1.8$ lines (range: 0-7 lines). The mean line gain was higher in central cone group than paracentral cone group and oval group than globus group $(p=.014, p=.045)$. The mean VAS score was $8.14 \pm 1.88$ (range: $6-10)$. Conclusions. Toris K can improve visual acuity of patients with keratoconus. Toris $\mathrm{K}$ is successful even in the moderate and advanced form of the disease.

\section{Introduction}

Keratoconus is a progressive, noninflammatory ocular disorder characterized by steepening and distortion of the cornea, apical thinning, and central scarring [1]. It is generally bilateral and progresses asymmetrically in both eyes [2]. Progressive ectasia and thinning of the cornea result in irregular astigmatism and visual symptoms [3].

Spectacles are useful in optical management of the early stages of keratoconus when the astigmatism is mild [4]. However, for moderate-to-advanced keratoconus, spectacles are not very useful for improving vision $[4,5]$. In this stage of the disease, when patients have serious irregular astigmatism, contact lenses become necessary [5]. Various options for contact lenses are available such as rigid gas permeable (RGP) lenses [6,7], hybrid contact lenses [8,9], piggyback lenses [10, $11]$, and scleral lenses $[12,13]$. RGP lenses are traditionally the first choice and have been commonly used because of their success in improving visual acuity [7]. RPG lenses improve visual acuity by their refractive power and also by providing a regular corneal surface. However, prolonged use of RGP lenses may lead to lens intolerance and ocular discomfort in most patients with keratoconus [14]. Another important disadvantage of RPG lenses is the potential for damage to the cornea $[15,16]$. Also sometimes, it is not possible to find the suitable RGP contact lens for each irregular corneal surface. In such cases, soft contact lenses should be considered. Toris $\mathrm{K}$ (SwissLens, Prilly, Switzerland) is an example of these kinds of lenses for keratoconus.

Soft contact lenses have their comfort advantages over RGPs but they do not provide a regular corneal surface as much as RGP lenses do. In this study, we aimed to evaluate the comfort and visual performance of Toris $\mathrm{K}$ soft contact lens in patients with moderate-to-advanced keratoconus. We also aimed to compare the visual performance of the contact lens in different cone shape (oval, nipplei globus), cone location 
TABLE 1: The fitting set parameters and the fitting assessment procedure of Toris K.

\begin{tabular}{lc}
\hline Technical data & Values \\
\hline Total diameter & $13.70 \mathrm{~mm}$ (HydroCone K12) \\
& $14.00 \mathrm{~mm}$ (HydroCone K34) \\
\hline Base curve & 7.20 to $8.40 \mathrm{D}$ \\
\hline Sphere & -40.0 to $+40.0 \mathrm{D}$ \\
\hline Cylinder & -0.01 to $-8.00 \mathrm{D}$ \\
\hline Axis & $0-180^{\circ}$ \\
\hline Center thickness & Standard K12 $=0.42 \mathrm{~mm}, \mathrm{~K} 34=0.52 \mathrm{~mm}$ \\
\end{tabular}

The Fitting Assessment Procedure

First contact lens choice

It is suggested working with trial lenses with cylindrical power $-0.01 \mathrm{D}$

Keratoconus classification

First apply topographical indications or follow the rules:

Vcc $>0.6$ and/or keratometry > 6.8: grade 1 or 2 (choose HydroCone K12)

$\mathrm{Vcc}<0.6$ and/or keratometry $<6.8$ : grade 3 or 4 (choose HydroCone K34)

Diameter and base curve selection

Add 0.8 diopters to the average $K$ value and then select a trial lens

HydroCone $\mathrm{K} 12 /$ total diameter $=14.00 \mathrm{~mm}$

HydroCone K34/total diameter $=13.70 \mathrm{~mm}$

Further steps

The first lens helps to validate base curve and total diameter

The patient should wait for $30 \mathrm{~min}$

Dynamic stabilization marks should be evaluated to measure the stabilization axis

Push-up test should be done

The fitting curve should demonstrate typical fitting of characteristics of a standard soft lens fit

If the fitting curve is too flat, there will be excessive movement and/or edge lift and then switch to a steeper trial lens

Little or no movement and/or edge impingement would indicate the fitting curve is too steep and then switch to a flatter trial lens

Overrefraction should be done

Prescription should include both spherical and cylindrical errors with its axis

In case of glare and/or halo, you can request to enlarge the optical zone

D: diopter and Vcc: best spectacle corrected visual acuity.

(central, paracentral), and severity of the disease (moderate, advanced).

\section{Methods}

In this retrospective study, we reviewed the records of patients with keratoconus who were fitted Torsi $\mathrm{K}$ contact lenses between December 2013 and December 2015. Written informed consent was obtained from all patients before the contact lenses fit. The study adhered to the tenets of the Declaration of Helsinki and local ethic committee approval was obtained. To be included in the study, each patient was required to have all of the following criteria: age $\geq 18$ years, a diagnosis of moderate-to-advanced keratoconus detected by thorough topographic evaluation in conjunction with the clinical examination, and mean corneal power $>45$ diopters (D).

Patients were not included in the study if they had a history of ocular surgery, history of ocular trauma, and any ocular disease (e.g., active ocular infection, clinically significant nuclear sclerosis/cataract, and retinal diseases) that might affect the results, and break-up time (BUT) under 10 seconds.

Data collected from the patients' records included age, gender, refractive errors, BUT, mean-steep-flat keratometric measurements and cone type-location from Sirius (Schwind eye-tech-solutions GmbH \& Co. KG, Kleinostheim, Germany) scan, uncorrected visual acuity (UCVA), best spectacle corrected visual acuity (BCVA), best contact lens corrected visual acuity (BCLCVA), base curve (BC) prescribed contact lens diopter, and visual analogue scales (VAS).

All participants underwent a standardized ophthalmologic examination including refraction, visual acuity (Snellen from 6 meters via Topcon ACP-8 chart projector (Topcon Corporation, Tokyo, Japan) under photopic condition $\left(85 \mathrm{~cd} / \mathrm{m}^{2}\right)$ luminance), slit-lamp biomicroscopy-fundoscopy, BUT, and corneal topography via Sirius.

After UCVA and BCVA were measured, contact lens was fitted as provided in its technical fitting guide and manufacturer's specifications were followed (Table 1). Toris $\mathrm{K}$ soft contact lens is a silicone hydrogel lens with front toric surface. 
It uses dynamic stabilization system with bumps at $0^{\circ}$ and $180^{\circ}$ engraved points. A dedicated set of lenses is needed for this purpose in different base curves and different peripheral radii with power. The lens was allowed to settle for approximately $5 \mathrm{~min}$ and then the movement, rotation, and centration were checked with a slit-lamp. After correct fit and patient comfort were achieved, residual refractive error was measured via retinoscopy. Then overrefraction was performed with correcting spectacle lenses and contact lenses were prescribed. BCLCVA and VAS score were measured a week later at the first visit of patients. VAS is previously used to rate comfort with contact lenses [14, 17]. VAS were administered by asking patients to record their subjective impressions of vision and comfort using a scale from 0 (lowest) to 10 (highest). The scale was horizontally oriented, measuring $10 \mathrm{~cm}$, and the value for statistical analysis was measured with a rule at the point where the mark was inserted by the patient.

In this study, according to the topographic map, cone location was classified as central (if the highest power was located in central $2 \mathrm{~mm}$ ) and paracentral (if the highest power was located out of central $2 \mathrm{~mm}$ ). With Keratoconus classified based on the mean $K$ reading on corneal topography, the patients were classified as mild in cases with $K$ value less than $45 \mathrm{D}$, moderate in cases with $K$ value between 45 and $52 \mathrm{D}$, and advanced in cases with $K$ value more than $52 \mathrm{D}[18,19]$.

Primary outcome measures included UCVA, BCVA, BCLCVA, VAS, and results in subgroups according to cone location and severity of keratoconus.

2.1. Statistical Analysis. Visual acuity was converted to the logarithm of the minimum angle of resolution (logMAR) for statistical analysis. Categorical variables were presented as numbers and percentages, while numerical variables were expressed as the mean and standard deviation. The Kolmogorov-Smirnov test was applied to assess the normal distribution of data. The outcomes were compared using appropriate tests (paired-samples $t$-test, independent-samples $t$-test, and one-way ANOVA). The Statistical Package for the Social Sciences version 23 (SPSS, Chicago, IL, USA) was used for data analysis, for which values of $p<.05$ were considered to be statistically significant.

\section{Results}

3.1. Demographic Characteristics. The study sample consisted of 60 eyes of 40 participants ( 17 females and 23 males), all of whom were Caucasian. The mean age was $27.3 \pm 8.6$ years (range: 18 to 54 ). Table 2 shows participants' demographic characteristics.

HydroCone K34 lenses were used for all participants. The mean base curve (BC) was $7.75 \pm 0.15$ (range: 7.40 to 8.20 ). The mean spherical and cylindrical power (D) of prescribed contact lens were $-2.89 \pm 2.43$ (range: -10 to 1 ) and $-2.02 \pm$ 1.08 (range: -4.25 to 0 ).

3.2. Visual Acuity. Table 3 shows the visual acuities. There was a significant difference between BCVA and BCLCVA $(p=$ $.000)$.
TABLE 2: Demographic information of the population enrolled in the study.

\begin{tabular}{|c|c|}
\hline Parameter & Values \\
\hline Number of patients & $n=40$ \\
\hline Females & $17(42.5 \%)$ \\
\hline Males & $23(57.5 \%)$ \\
\hline \multicolumn{2}{|l|}{ Age } \\
\hline$($ mean $\pm s d)$ & $27.3 \pm 8.6$ \\
\hline$(\min . / \max )$. & $18 / 54$ \\
\hline Number of eyes & $n=60$ \\
\hline Bilateral & 20 patients \\
\hline Unilateral & 20 patients \\
\hline Refractive error (D) & $n=46$ \\
\hline \multicolumn{2}{|l|}{ Spherical } \\
\hline$($ mean $\pm s d)$ & $-3.31 \pm 3.62$ \\
\hline$(\min . / \max )$. & $-15 / 2.75$ \\
\hline \multicolumn{2}{|l|}{ Cylindrical } \\
\hline$($ mean $\pm s d)$ & $-3.94 \pm 1.72$ \\
\hline$(\min . / \max )$. & $-8 / 0$ \\
\hline Keratometry (D) & $n=60$ \\
\hline \multicolumn{2}{|l|}{ Flat } \\
\hline$($ mean $\pm s d)$ & $47.45 \pm 3.56$ \\
\hline$(\min . / \max )$. & $42.72 / 60.27$ \\
\hline \multicolumn{2}{|l|}{ Steep } \\
\hline$($ mean $\pm \mathrm{sd})$ & $50.85 \pm 3.89$ \\
\hline$(\min . / \max )$. & $46.10 / 63.82$ \\
\hline \multicolumn{2}{|l|}{$\operatorname{SimK}$} \\
\hline$($ mean $\pm s d)$ & $49.10 \pm 3.66$ \\
\hline (min./max.) & $45.02 / 61.72$ \\
\hline
\end{tabular}

D: diopter and sd: standard deviation.

When we divided the patients into subgroups according to cone type, there was no significant difference in UCVA and BCVA between groups ( $p=.091, p=.817$, one-way ANOVA) but there was a significant difference in BCLCVA between groups ( $p=.029$, one-way ANOVA). Post hoc Tukey test showed that BCLCVA was significantly better in oval type than globus type $(p=.022)$.

When we divided the patients into subgroups according to cone location, there was no significant difference in UCVA, BCVA, and BCLCVA between groups $(p=.610 ; p=.630$; $p=.468$ (independent-samples $t$-test)).

When we divided the patients into subgroups according to the severity of keratoconus, UCVA and BCLCVA were significantly better in moderate keratoconus group $(p=.015$, $p=.018$, independent-samples $t$-test). There was no difference in BCVA between groups $(p=.085)$.

Figure 1 shows line gains in Snellen. The mean line gain in Snellen between BCVA and BCLCVA was $3.6 \pm 1.8$ lines (range: $0-7$ lines). 45 patients (75\%) gained 3 or more lines with contact lens correction against spectacle correction. Two patients $(3.33 \%)$ gained no lines but gained only 2 letters. However, those patients expressed that their subjective vision was better with contact lens. There was no significant difference in the mean line gain between moderate 
TABLE 3: Visual acuity (logMAR, mean $\pm \mathrm{sd}, \min . / \max$.$) .$

\begin{tabular}{|c|c|c|c|c|}
\hline & UCVA & BCVA & BCLCVA & Mean gain line \\
\hline \multirow{2}{*}{ All eyes } & $0.85 \pm 0.38$ & $0.47 \pm 0.27$ & $0.16 \pm 0.20$ & $3.6 \pm 1.8$ \\
\hline & $0.30 / 1.30$ & $0.10 / 1.30$ & $0 / 1.00$ & $0 / 7$ \\
\hline \multicolumn{5}{|l|}{ Cone types } \\
\hline \multirow{2}{*}{ Oval $(n=18,30 \%)$} & $0.79 \pm 0.30$ & $0.43 \pm 0.23$ & $0.08 \pm 0.09$ & $4.0 \pm 1.7$ \\
\hline & $0.30 / 1.30$ & $0.10 / 1.00$ & $0.00 / 0.20$ & $1 / 7$ \\
\hline \multirow{2}{*}{ Nipple $(n=31,51.67 \%)$} & $0.81 \pm 0.40$ & $0.48 \pm 0.31$ & $0.14 \pm 0.19$ & $3.7 \pm 1.8$ \\
\hline & $0.30 / 1.30$ & $0.10 / 1.30$ & $0.00 / 1.00$ & $0 / 6$ \\
\hline \multirow{2}{*}{ Globus $(n=11,18.33 \%)$} & $1.08 \pm 0.36$ & $0.49 \pm 0.20$ & $0.25 \pm 0.20$ & $2.4 \pm 1.6$ \\
\hline & $0.30 / 1.30$ & $0.20 / 0.70$ & $0.00 / 0.70$ & $0 / 5$ \\
\hline \multicolumn{5}{|l|}{ Cone location } \\
\hline \multirow{2}{*}{ Central $(n=48,80 \%)$} & $0.85 \pm 0.38$ & $0.47 \pm 0.28$ & $0.13 \pm 0.18$ & $3.8 \pm 1.8$ \\
\hline & $0.30 / 1.30$ & $0.10 / 1.30$ & $0.00 / 1.00$ & $0 / 7$ \\
\hline \multirow{2}{*}{ Paracentral $(n=12,20 \%)$} & $0.91 \pm 0.38$ & $0.43 \pm 0.24$ & $0.17 \pm 0.14$ & $2.4 \pm 1.2$ \\
\hline & $0.30 / 1.30$ & $0.10 / 0.70$ & $0.00 / 0.40$ & $1 / 4$ \\
\hline \multicolumn{5}{|l|}{ Severity of keratoconus } \\
\hline \multirow{2}{*}{ Moderate $(n=50,83.3 \%)$} & $0.81 \pm 0.36$ & $0.44 \pm 0.25$ & $0.12 \pm 0.16$ & $3.7 \pm 1.8$ \\
\hline & $0.30 / 1.30$ & $0.10 / 1.30$ & $0.00 / 1.00$ & $0 / 7$ \\
\hline \multirow{2}{*}{ Advanced $(n=10,16.7 \%)$} & $1.12 \pm 0.38$ & $0.60 \pm 0.32$ & $0.26 \pm 0.20$ & $2.7 \pm 1.8$ \\
\hline & $0.30 / 1.30$ & $0.20 / 1.30$ & $0.00 / 0.70$ & $0 / 6$ \\
\hline
\end{tabular}

UCVA: uncorrected visual acuity, BCVA: best-corrected visual acuity, BCLCVA: best contact lens corrected visual acuity, sd: standard deviation, and D: diopter.

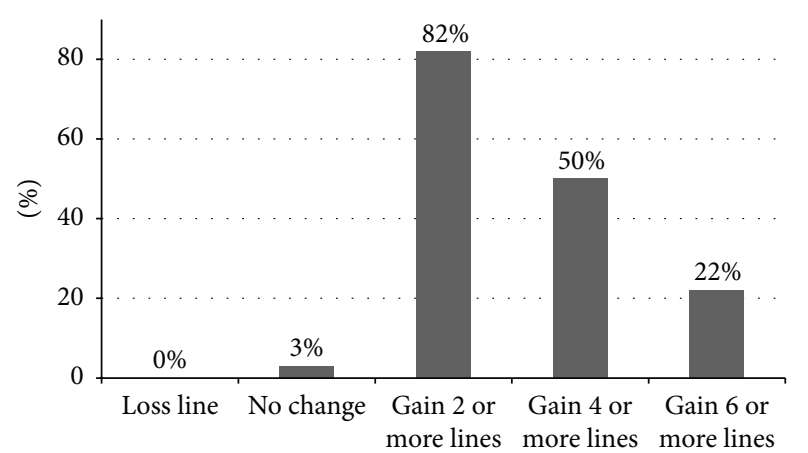

FIGURE 1: Line gains in Snellen with contact lens (difference between BCLCVA and BCVA).

keratoconus group and advanced keratoconus group ( $p=$ .104 , independent-samples $t$-test). The mean line gain was higher in central cone group than paracentral cone group ( $p=.014$, independent samples $t$-test). There was significant difference in the mean line gain between oval-nipple-globus groups ( $p=.045$, one-way ANOVA). The post hoc Tukey test showed that the difference was between oval and globus type and the mean gain line was significantly higher in oval group $(p=.045)$.

The mean VAS score was $8.14 \pm 1.88$ (range: $6-10$ ).

\section{Discussion}

Contact lenses have an important role in the management of visual symptoms of patients with keratoconus. The purpose of fitting contact lenses in such patients is to improve visual acuity with comfort [4]. It is well known that RPG contact lenses produce good visual acuity results and improve patients' quality of life [7]. Yazar et al. showed that RPG contact lenses may cause some serious complications such as corneal erosion, hidrops, allergic conjunctivitis, and dry eye [20]. Another downside of RPG lenses is that many patients cannot tolerate them because of comfort issues [8]. Soft contact lenses are known for comfort and they may be a good alternative to RGP lenses in patients who experienced intolerance to RGP lenses [21].

Gumus and Kahraman reported results of Toris K contact lens in keratoconus [22]. In their study, comfort score was classified as good/excellent in 46 eyes (92\% of participants) and moderate in only 4 eyes ( $8 \%$ of participants) [22]. Similarly, comfort scores were high in our study. The high VAS score provides strong evidence that patients who cannot tolerate RGP lenses due to discomfort may find Toris $\mathrm{K}$ contact lens an acceptable option.

In Gumus and Kahraman study, the mean increase in visual acuity was reported 4.5 lines (range: 1 to 9 lines). 92\% of their participants classified their visual acuity as good/ excellent in daytime, and $76 \%$ were classified as good/excellent in nighttime [22]. In the present study, the mean visual acuity was significantly better with the contact lens than with spectacles and improved to $0.16 \pm 0.20 \log$ MAR from 0.47 $\pm 0.27 \log$ MAR. The mean line gain was over 3 lines. Good visual results show to us that Toris $\mathrm{K}$ is effective for treatment of visual symptom of moderate-to-advanced keratoconus.

This study is the first study in literature that compares the visual results of Toris $\mathrm{K}$ contact lens fitting in keratoconus subtypes (cone type, cone location, and severity of keratoconus). Romero-Jiménez et al. compared the optimal lens fit 

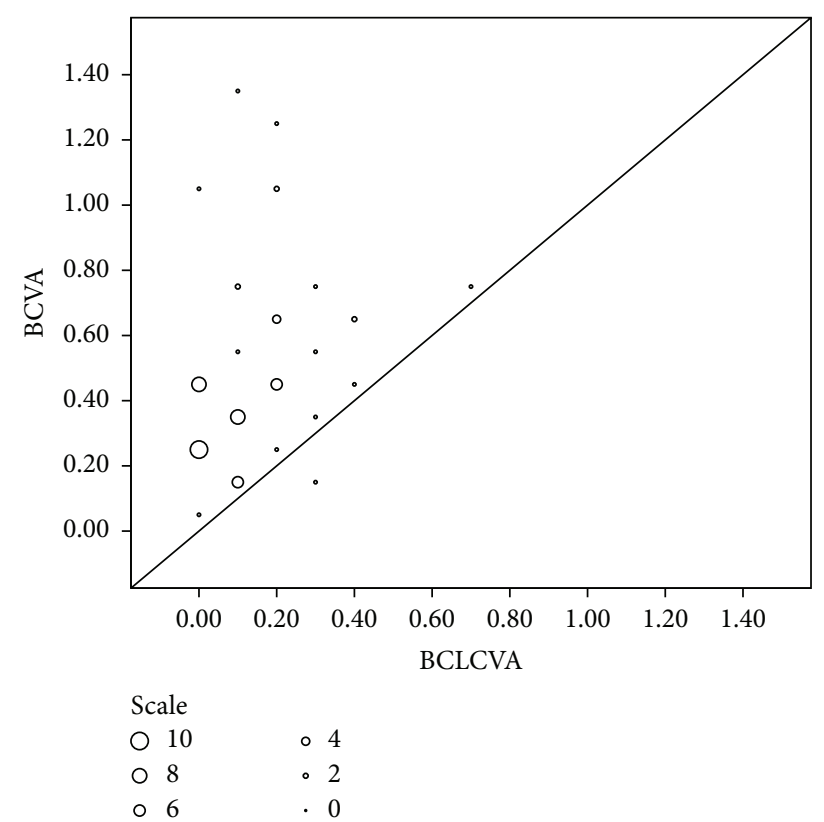

Figure 2: BCLCVA versus BCVA (logMAR).

rates between nipple and oval cones in the literature [23]. We added visual results comparisons in keratoconus subtypes to the literature. Results show us that BCLCVA and the mean line gain were better in oval cones than globus cones (Figure 2). We still got improvements with contact lens in globus group. However, we believe that visual management of globus type cones is harder than other types with soft contact lenses and another contact lens type or surgical options may be necessary.

The mean visual acuity with contact lens was better in moderate keratoconus group than advanced group. It is proved that contact lens vision correction is more successful at the early stages of the disease.

Nejabat et al. showed that the cone location has no effect on the RGP corrected visual acuities in patients with keratoconus [19]. Similarly, this study showed that the cone location (central or paracentral) has no effect on the Toris $\mathrm{K}$ soft contact lens corrected visual acuities. However, the mean gain line was higher in central cone group.

This study has limitations. Retrospective nature of the study is a limitation. Also this study does not show the lens behaviors, complications, in the long term. It is well-known that soft contact lenses are thick and cause some complications, due to hypoxia, such as corneal swelling, contact lens induced papillary conjunctivitis, and superior punctuate keratitis [24, 25].

The strongest aspect of the study is that being first report in the literature that examines the visual results of Toris $\mathrm{K}$ contact lens in different subtypes (cone type, cone location, and severity of keratoconus) of keratoconus. Finally, reduced sample size in some subgroup comparisons may count as a limitation.

In sum, Toris $\mathrm{K}$ contact lenses may improve visual acuity with comfort in patients with keratoconus. Toris $\mathrm{K}$ is successful even in the moderate and advanced form of the disease.
Further studies with longer follow-up period that compared the different soft contact lenses are needed.

\section{Competing Interests}

The authors declare that they have no competing interests.

\section{References}

[1] E. Yazar, F. Alaçayır, A. A. Altınok, K. Serdar, and F. Öztürk, "Keratokonuslu hastalarda gaz geçirgen sert kontakt lens uygulama sonuçlarımız," Turkish Journal of Ophthalmology, vol. 43, no. 6, pp. 432-436, 2013.

[2] H. Ali Bayhan, S. Aslan Bayhan, C. Gürdal, T. Takmaz, and I. Can, "Keratokonus tanisinda optik koherens tomografi ile pakimetrik haritalama," Türk Oftalmoloji Derneği, vol. 43, no. 4, pp. 236-240, 2013.

[3] Z. Tuncer and T. Soylu, "İleri keratokonuslu olgularda kontakt lens uygulaması: uzun süreli takip sonuçlarımız," Turkish Journal of Ophthalmology, vol. 42, no. 3, pp. 202-206, 2012.

[4] V. M. Rathi, P. S. Mandathara, and S. Dumpati, "Contact lens in keratoconus," Indian Journal of Ophthalmology, vol. 61, no. 8, pp. 410-415, 2013.

[5] A. Altun, S. A. Kurna, T. Sengor, G. Altun, O. O. Olcaysu, and M. H. Simsek, "Success of hydrocone (TORIS-K) soft contact lens for keratoconus and traumatic keratopathy," Pakistan Journal of Medical Sciences, vol. 31, no. 4, pp. 995-998, 2015.

[6] U. D. Uzunel, T. Kusbeci, B. Yuce, and B. Yüksel, "Effects of rigid contact lenses on optical coherence tomographic parameters in eyes with keratoconus," Clinical and Experimental Optometry, vol. 98, no. 4, pp. 319-322, 2015.

[7] Y. Wu, Q. Tan, W. Zhang et al., "Rigid gas-permeable contact lens related life quality in keratoconic patients with different grades of severity," Clinical and Experimental Optometry, vol. 98, no. 2, pp. 150-154, 2015.

[8] G. Carracedo, J. M. González-Méijome, D. Lopes-Ferreira, J. Carballo, and L. Batres, "Clinical performance of a new hybrid contact lens for keratoconus," Eye and Contact Lens, vol. 40, no. 1, pp. 2-6, 2014.

[9] D. P. Piñero, R. J. Pérez-Cambrodí, P. Ruiz-Fortes, and F. J. Blanes-Mompó, "New-generation hybrid contact lens for the management of extreme irregularity in a thin cornea after unsuccessful excimer laser refractive surgery," Eye and Contact Lens, vol. 40, no. 3, pp. e16-e20, 2014.

[10] B. T. Acar, E. T. Vural, and S. Acar, "Effects of contact lenses on the ocular surface in patients with keratoconus: piggyback versus clearkone hybrid lenses," Eye and Contact Lens, vol. 38, no. 1, pp. 43-48, 2012.

[11] T. Sengor, S. A. Kurna, S. Aki, and Y. Özkurt, "High Dk piggyback contact lens system for contact lens-intolerant keratoconus patients," Clinical Ophthalmology, vol. 5, no. 1, pp. 331-335, 2011.

[12] M. M. Schornack and S. V. Patel, "Scleral lenses in the management of keratoconus," Eye and Contact Lens, vol. 36, no. 1, pp. 39-44, 2010.

[13] K. W. Pullum, M. A. Whiting, and R. J. Buckley, "Scleral contact lenses: the expanding role," Cornea, vol. 24, no. 3, pp. 269-277, 2005.

[14] H. Fujita, K. Sano, S. Sasaki et al., "Ocular discomfort at the initial wearing of rigid gas permeable contact lenses," Japanese Journal of Ophthalmology, vol. 48, no. 4, pp. 376-379, 2004. 
[15] J. S. Hwang, J. H. Lee, W. R. Wee, and M. K. Kim, "Effects of multicurve RGP contact lens use on topographic changes in keratoconus," Korean Journal of Ophthalmology, vol. 24, no. 4, pp. 201-206, 2010.

[16] F. J. Fernandez-Velazquez, "Kerasoft IC compared to Rose-K in the management of corneal ectasias," Contact Lens and Anterior Eye, vol. 35, no. 4, pp. 175-179, 2012.

[17] J. M. González-Méijome, G. Carracedo, J. González-Pérez, A. Peral, J. Jorge, and S. C. Peixoto-De-Matos, "Comfort and vision scores at insertion and removal during 1 month of wear of paragon CRT for corneal reshaping," Eye and Contact Lens, vol. 37, no. 5, pp. 302-306, 2011.

[18] K. Zadnik, J. T. Barr, M. O. Gordon, and T. B. Edrington, "Biomicroscopic signs and disease severity in keratoconus," Cornea, vol. 15, no. 2, pp. 139-146, 1996.

[19] M. Nejabat, M. R. Khalili, and C. Dehghani, "Cone location and correction of keratoconus with rigid gas-permeable contact lenses," Contact Lens and Anterior Eye, vol. 35, no. 1, pp. 17-21, 2012.

[20] E. Yazar, F. Alacayır, A. A. Altınok, K. Serdar, and F. Ozturk, "Results of application of rigid gas permeable contact lenses in patients with keratoconus," Turkish Journal of Ophthalmology, vol. 43, pp. 432-436, 2013.

[21] A. Jinabhai, H. Radhakrishnan, C. Tromans, and C. O'Donnell, "Visual performance and optical quality with soft lenses in keratoconus patients," Ophthalmic and Physiological Optics, vol. 32, no. 2, pp. 100-116, 2012.

[22] K. Gumus and N. Kahraman, "A new fitting approach for providing adequate comfort and visual performance in keratoconus: soft HydroCone (Toris K) lenses," Eye and Contact Lens, 2015.

[23] M. Romero-Jiménez, J. Santodomingo-Rubido, and J. M. González-Méijome, "An assessment of the optimal lens fit rate in keratoconus subjects using three-point-touch and apical touch fitting approaches with the rose K2 lens," Eye and Contact Lens, vol. 39, no. 4, pp. 269-272, 2013.

[24] G. Tyagi, M. Collins, S. Read, and B. Davis, "Regional changes in corneal thickness and shape with soft contact lenses," Optometry and Vision Science, vol. 87, no. 8, pp. 567-575, 2010.

[25] T. Nagachandrika, U. Kumar, S. Dumpati, S. Chary, P. S. Mandathara, and V. M. Rathi, "Prevalence of contact lens related complications in a tertiary eye centre in India," Contact Lens and Anterior Eye, vol. 34, no. 6, pp. 266-268, 2011. 


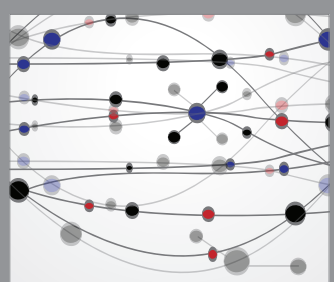

The Scientific World Journal
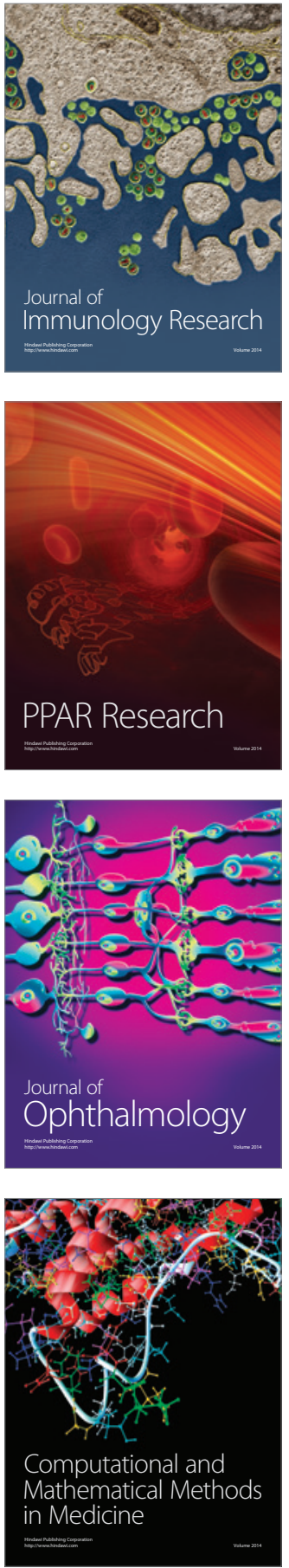

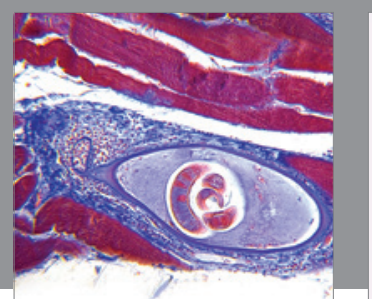

Gastroenterology Research and Practice

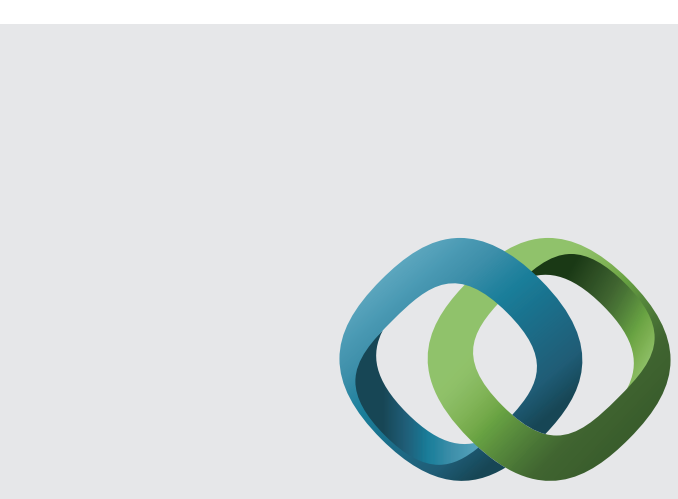

\section{Hindawi}

Submit your manuscripts at

http://www.hindawi.com
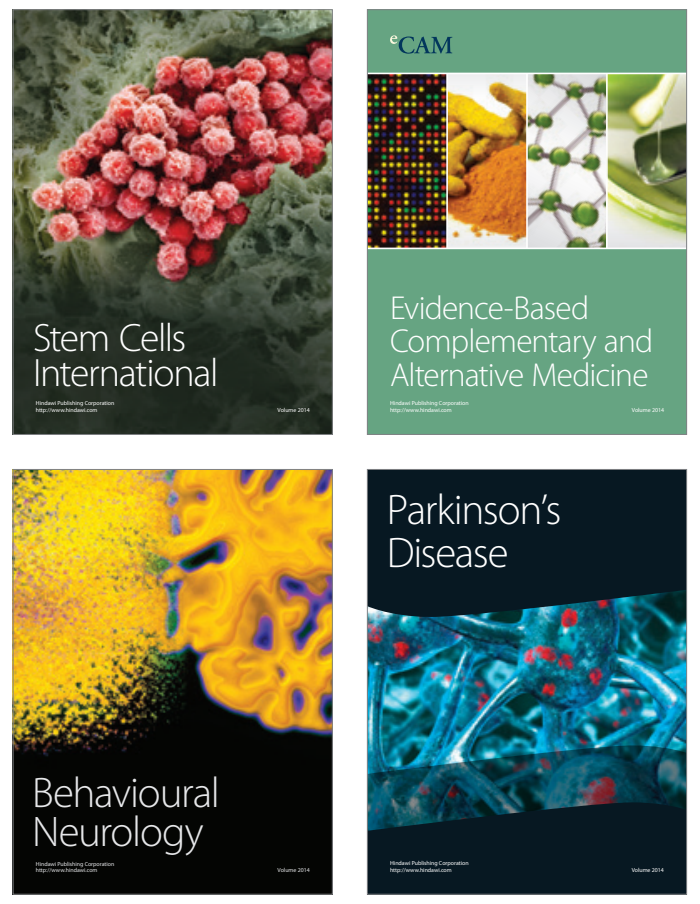
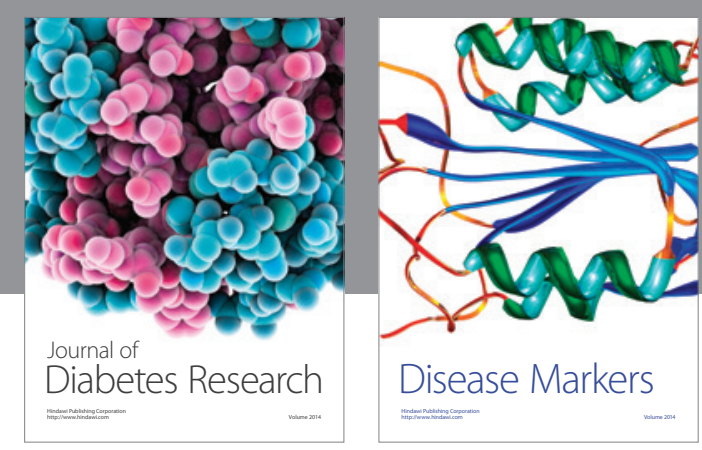

Disease Markers
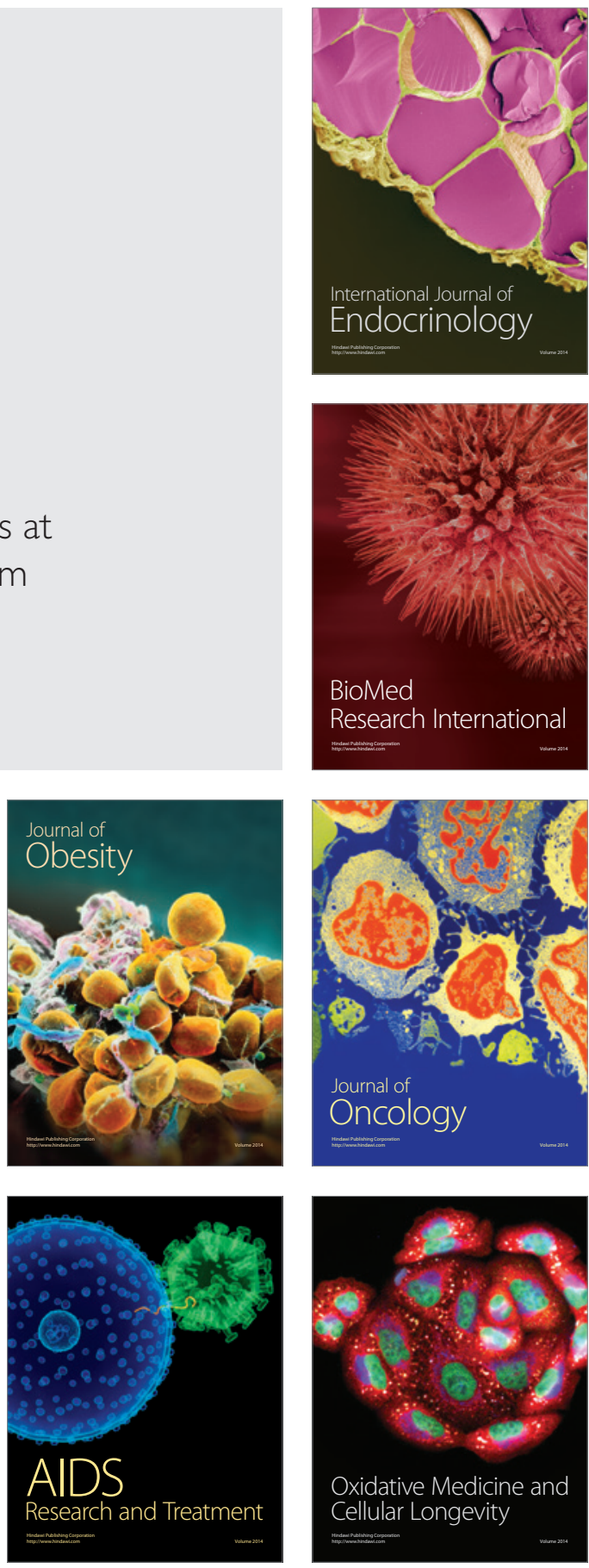